\section{Do ACR TI-RADS scores demonstrate unique thyroid molecular profiles?}

\author{
Rong Xia', Wei Sun', Joseph Yee², Sheila Sheth², Chrystia Slywotzky², Steven Hodak², \\ Tamar C. Brandler' \\ Departments of ${ }^{1}$ Pathology and ${ }^{2}$ Radiology, ${ }^{3}$ Department of Medicine, Division of \\ Endocrinology, NYU Langone Health, New York, NY, USA
}

Purpose: The present study aimed to examine the molecular profiles of cytologically indeterminate thyroid nodules stratified by American College of Radiology Thyroid Imaging Reporting and Data System (TI-RADS) categories and to determine whether certain ultrasonographic features display particular molecular alterations.

Methods: A retrospective review was conducted of cases from January 1, 2016 to April 1, 2018. Cases with in-house ultrasonography, fine-needle aspiration Bethesda System for Reporting Thyroid Cytopathology (TBSRTC) diagnoses, molecular testing, and surgery were included. All cases were diagnosed as TBSRTC indeterminate categories. The ultrasound studies were retrospectively reviewed and assigned TI-RADS scores (TR1-TR5) by board-certified radiologists. The final diagnoses were determined based on the surgical resection pathology. Binary logistic regression analysis was used to study whether demographic characteristics, TI-RADS levels, and TBSRTC diagnoses were associated with ThyroSeq molecular results.

Results: Eighty-one cases met the inclusion criteria. RAS mutations were the most common alteration across all TI-RADS categories (TR2 2/2; TR3 10/19, TR4 13/44, and TR5 8/16), and did not stratify with any particular TI-RADS category. Only TR4 and TR5 categories displayed more aggressive mutations such as $B R A F^{\mathrm{V} 600 \mathrm{E}}$ and TERT. ThyroSeq results were positively correlated with thyroid malignancy when non-invasive follicular thyroid neoplasm with papillary-like nuclear features (NIFTP) was categorized in the malignant category (odds ratio [OR], 6.859; $\mathrm{P}<0.01$ ), but not when NIFTP was removed from the malignancy category. Echogenicity scores were found to be negatively correlated with ThyroSeq results in thyroid nodules $(O R, 0.162 ; P<0.01)$.

Conclusion: Higher-risk molecular alterations tended to stratify with the higher TI-RADS categories.

Keywords: Thyroid nodule; American College of Radiology Thyroid Imaging Reporting and Data System; ThyroSeq; Cytology; Fine-needle aspiration

Key points: Higher-risk molecular alterations tended to stratify with higher Thyroid Imaging Reporting and Data System categories; however, some alterations presented in both benign and neoplastic or malignant entities (e.g., RAS alterations). Only TR4 and TR5 categories displayed more aggressive mutations such as $B R A F^{\mathrm{V} 600 \mathrm{E}}$ and TERT. Echogenicity scores were negatively correlated with genetic alterations, but should be viewed together with other sonographic features.

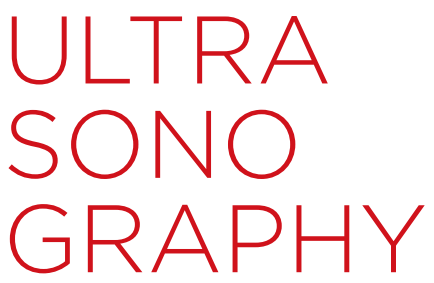

\section{ORIGINAL ARTICLE}

https://doi.org/10.14366/usg.21130 pISSN: 2288-5919 • elSSN: 2288-5943

Ultrasonography 2022;41:480-492

Received: June 19, 2021

Revised: December 13, 2021

Accepted: December 20, 2021

Correspondence to:

Tamar C. Brandler, MD, MS, Department of Pathology, New York University Langone Health, 560 First Avenue Tisch Hospital, Room 451, New York, NY 10016, USA

Tel. +1-212-263-5470

Fax. +1-212-263-7916 E-mail:Tamar.Brandler@nyulangone. org

\footnotetext{
This is an Open Access article distributed under the terms of the Creative Commons Attribution NonCommercial License (http://creativecommons.org/ licenses/by-nc/4.0/) which permits unrestricted noncommercial use, distribution, and reproduction in any medium, provided the original work is properly cited.
}

Copyright (C) 2022 Korean Society of Ultrasound in Medicine (KSUM)

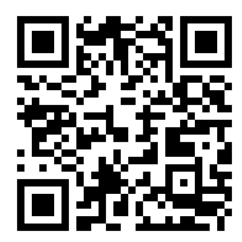

How to cite this article:

Xia R, Sun W, Yee J, Sheth S, Slywotzky C, Hodak S, et al. Do ACR TI-RADS scores demonstrate unique thyroid molecular profiles?. Ultrasonography. 2022 Jul;41(3):480492. 


\section{Introduction}

Thyroid nodules occur commonly, with a prevalence of $68 \%$ in the adult population of the United States $[1,2]$. The incidence of thyroid cancer has increased during recent years with a decrease in the size of malignant nodules $[3,4]$. Improvement in ultrasound technology and increases in incidental detection may account for the increase in smaller malignant nodules [5]. In 2017, the American College of Radiology (ACR) published the 5-level classification system Thyroid Imaging Reporting and Data System (TI-RADS) based on both ultrasound characteristics and nodule size to stratify the risk of malignancy as determined by ultrasound features $[2,6,7]$, including composition, echogenicity, shape, margin, and echogenic foci. It has been reported that the TI-RADS criteria have good concordance with The Bethesda System for Reporting Thyroid Cytopathology (TBSRTC), especially in benign nodules [8].

Fine-needle aspiration (FNA) cytology is regarded as the most efficient method for evaluating thyroid lesions $[9,10]$. Thyroid FNA cytology samples are categorized using TBSRTC at most institutions [10], with accuracy rates ranging from $62 \%$ to $85 \%$ $[11,12]$. Indeterminate TBSRTC diagnostic categories (category III lesions, atypia of undetermined significance/follicular lesion of undetermined significance [AUS/FLUS]; category IV, follicular neoplasm/suspicious for follicular neoplasm [FN/SFN]; and category $\mathrm{V}$, suspicious for malignancy) may pose diagnostic challenges and comprise up to $25 \%$ of FNA cytology diagnoses [10]. Moreover, there is no consensus on the standard of care and management for cytologically indeterminate thyroid nodules. Of note, genetic alterations are detected in approximately $90 \%$ of papillary thyroid carcinomas (PTCs), and more than $60 \%$ of thyroid malignancies [13-22]. Therefore, in order to further risk-stratify patients with indeterminate thyroid cytology diagnoses, molecular studies have been utilized to detect genetic alterations and play an important role in the therapeutic triage of thyroid lesions $[13,14]$. Molecular tests demonstrate a high negative predictive value $(92 \%-96 \%)$ in thyroid nodules $[13,14,23]$. Accordingly, diagnostic hemithyroidectomy can be avoided in approximately $50 \%-60 \%$ of indeterminate FNA cytology cases with adjunctive molecular testing.

As up to $25 \%$ of thyroid nodules yield indeterminate FNA cytology requiring molecular evaluation, but not all indeterminate FNAs have the same TI-RADS scores, it was hypothesized that particular ultrasonographic features may be associated with certain molecular alterations. The present study analyzed the molecular profiles of thyroid nodules stratified by TI-RADS categories, as assigned retrospectively by board-certified radiologists with expertise in ultrasonography, and evaluated the correlation between molecular alterations and TI-RADS scores.

\section{Materials and Methods}

\section{Compliance with Ethical Standards}

The Study was approved by the Institutional Review Board of NYU Langone Health (i19-00812). The requirement for informed consent was waived because the study was retrospective and involved no more than minimal risk to privacy.

\section{Data Collection}

A retrospective study was performed to analyze the correlation between ACR TI-RADS ultrasound findings and molecular alterations in TBSRTC indeterminate (categories III-V) thyroid nodules. FNA biopsies performed on adults from January 1, 2016 to April 1, 2018 accompanied with follow-up molecular testing results and final surgical resection histopathology reports were included in the study. The information collected included ACR TI-RADS points and levels, patient demographics, FNA cytology results, molecular testing results, and final surgical outcomes.

Between January 1, 2016 and April 1, 2018 there were 765 ultrasound-guided FNA biopsies of thyroid nodules at our institution with subsequent ThyroSeq molecular testing, with cytologic classifications of indeterminate categories (TBSRTC III to V). Of these 765 cases, 638 did not have surgical follow-up data available. Of note, 413 of the 638 cases displayed negative ThyroSeq test results, and therefore were not scheduled for surgical resection. Surgical follow-up data were available for 127 of the 765 cases, of which 81 cases had preceding in-house ultrasound images for review. Therefore, 81 cases with in-house ultrasound images for review, FNA cytology diagnoses, in-house surgical resection pathology, and molecular studies were selected for this study (Fig. 1).

\section{ACR TI-RADS}

The sonographic features of each thyroid nodule were reported according to the published ACR TI-RADS guidelines. All ultrasound imaging was re-evaluated by two senior radiologists (J.Y. and S.S.), blinded to the original ultrasound diagnosis, to reach a consensus on the final diagnosis using the new ACR TI-RADS system. If a discrepancy existed between the two radiologists, a third senior radiologist (C.S.) evaluated the case and the final diagnosis was established on the consensus diagnosis of at least two radiologists. Briefly, the thyroid nodules were scored based on their size and five ultrasound features: composition, echogenicity, shape, margins, and the presence of echogenic foci. The ACR TI-RADS levels (TR1-TR5) were then determined by summarizing points for the five ultrasound features (Table 1). 


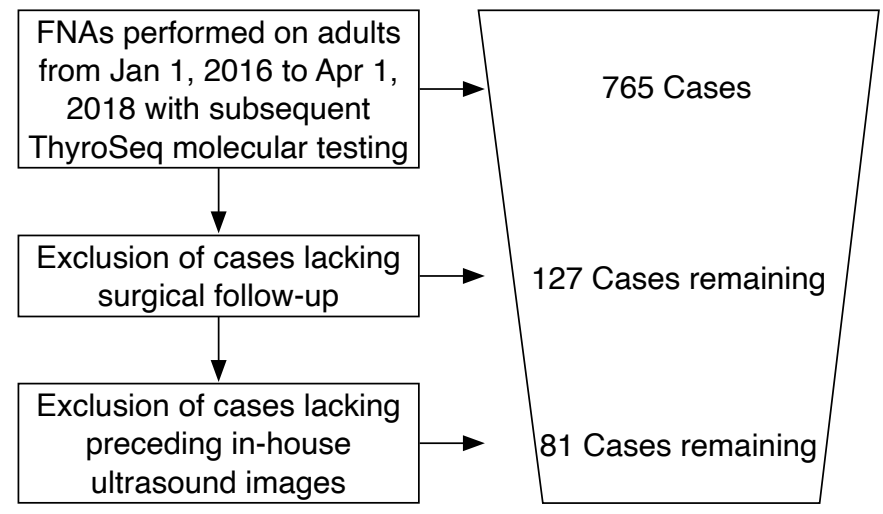

Fig. 1. Study flowchart. Initially, there were 765 ultrasound-guided thyroid fine-needle aspiration (FNA) biopsies of thyroid nodules at the authors' institution with subsequent ThyroSeq molecular testing between January 1, 2016 and April 1, 2018. After excluding 638 cases lacking surgical follow-up data (127 cases remaining), only 81 cases that had preceding in-house ultrasound images for review were kept in this study. These 81 cases all had preceding in-house thyroid ultrasound images, in-house cytology FNA, and ThyroSeq molecular results.

\section{FNA Procedure}

Ultrasound-guided thyroid FNA biopsies were performed by expert radiologists, endocrinologists, or cytopathologists with 23- to 27-gauge needles and 2 to 4 passes. The smears were air-dried and were stained with Diff-Quick and Ultrafast Papanicolaou. The smears were evaluated using the 2017 TBSRTC as the following categories: (I) non-diagnostic/unsatisfactory, (II) benign, (III) AUS/FLUS, (IV) FN/ SFN, (V) suspicious for malignancy, and (VI) positive for malignancy [10].

\section{Molecular Study}

All the FNA needles were routinely washed after each pass in ThyroSeq Preserve vials provided by ThyroSeq (CBLPath Laboratories, Rye Brook, NY, USA) in order to guarantee availability should those cases be diagnosed as cytologically indeterminate. ThyroSeq is a DNA- and RNA-based next-generation sequencing assay that analyzes genes for a variety of genetic alterations.

After receiving a cytologically indeterminate diagnosis, the

Table 1. Cytologic, surgical, and molecular diagnoses with demographic data for TI-RADS TR 2-5 nodules

\begin{tabular}{|c|c|c|c|c|c|}
\hline & $\operatorname{TR} 2(n=2)$ & TR3 $(n=19)$ & TR4 $(n=44)$ & TR5 $(n=16)$ & Total $(n=81)$ \\
\hline Age (year) & 40.0 & 42.7 & 53.5 & 54.8 & $50.6^{a)}$ \\
\hline Sex (male:female) & $0: 2$ & $5: 14$ & $10: 34$ & $5: 11$ & 20:61 \\
\hline \multicolumn{6}{|l|}{ Cytologic diagnosis } \\
\hline $\mathrm{TBS}\|\|^{\mathrm{b})}$ & $1(R A S, 1)$ & $\begin{array}{c}12 \text { (Neg, 3; RAS, 6; EIF1AX, 1; } \\
\text { TSHR, 1; DICER, 1) }\end{array}$ & 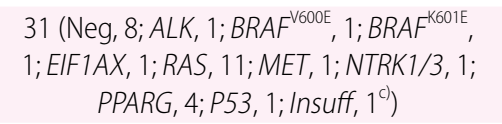 & $\begin{array}{c}10(\text { Neg, } 2 ; R A S, 6 ; P 53,1 ; \\
\left.B R A F^{\mathrm{K} 601 \mathrm{E}}, 1\right)\end{array}$ & 54 \\
\hline$T B S I^{b)}$ & $1(R A S, 1)$ & $6(\mathrm{Neg}, 1 ; R A S, 4 ;$ GEP-P, 1$)$ & $\begin{array}{c}12 \text { (Neg, 3; RAS, 2; MET, 2; GEP-P, 1; PPARG, } \\
1 ; \text { TERT, 1;P53, 2) }\end{array}$ & $\begin{array}{c}4(\text { Neg, } 1 ; \text { RAS, 1; TERT, } 1 ; \\
\text { IGF2BP3, 1) }\end{array}$ & 23 \\
\hline TBS $V^{b)}$ & 0 & $1(P P A R G, 1)$ & $1(N \operatorname{TRK} 1 / 3,1)$ & $2($ RAS, $1 ; \mathrm{Neg}, 1)$ & 4 \\
\hline \multicolumn{6}{|l|}{ Surgical diagnosis } \\
\hline \multicolumn{6}{|l|}{ Benign } \\
\hline FA & 0 & $\begin{array}{c}6(\mathrm{Neg}, 3 ; \text { RAS, } 1 ; \text { TSHR, } 1 ; \\
\text { GEP-P, 1) }\end{array}$ & $\begin{array}{c}12 \text { (Neg, 3; RAS, 5; EIF1AX, 1; MET, 1; P53, 1; } \\
\text { GEP-P, 1) }\end{array}$ & $2(R A S, 1 ; P 53,1)$ & 20 \\
\hline $\mathrm{NH}$ & $1(R A S, 1)$ & $1($ Neg, 1$)$ & $6\left(\right.$ Neg, $3 ;$ MET, 1; P53, 1; Insuff, $\left.1^{c)}\right)$ & $5(\mathrm{Neg}, 1 ; R A S, 4)$ & 13 \\
\hline Others & 0 & 0 & $3(\mathrm{Neg}, 3)$ & $1(I G F 2 B P 3,1)$ & 4 \\
\hline NIFTP & $1(R A S, 1)$ & $8(R A S, 6 ;$ EIF1AX, 1; DICER, 1) & $13\left(\mathrm{Neg}, 1 ; R A S, 7 ; B R A F^{\mathrm{K} 601 \mathrm{E}}, 1 ; P P A R G, 4\right)$ & $1(R A S, 1)$ & 23 \\
\hline \multicolumn{6}{|l|}{ Thyroid cancer } \\
\hline Conv-PTC & 0 & $2(R A S, 1 ; P P A R G, 1)$ & $3\left(B R A F^{\mathrm{V} 600 \mathrm{E}}, 1 ; \mathrm{MET}, 1 ; \mathrm{NTRK} 1 / 3,1\right)$ & 5 (Neg, 3; RAS, 2) & 10 \\
\hline FVPTC & 0 & $2(R A S, 2)$ & $\begin{array}{c}5(R A S, 1 ; A L K, 1 ; N T R K 1 / 3,1 ; \text { Neg, } 1 ; \\
\text { PPARG } 1)\end{array}$ & $1\left(B R A F^{K 601 E}, 1\right)$ & 8 \\
\hline FC & 0 & 0 & $2($ TERT, $1 ; P 53,1)$ & $1($ TERT, 1$)$ & 3 \\
\hline
\end{tabular}

TI-RADS, Thyroid Imaging Reporting and Data System; GEP-P, genetic expression profile positive; FA, follicular adenoma; NH, nodular hyperplasia; NIFTP, noninvasive follicular thyroid neoplasm with papillary-like features; Conv-PTC, conventional papillary thyroid carcinoma; FVPTC, follicular variant of papillary thyroid carcinoma; FC, follicular carcinoma; Neg, negative; Insuff, insufficient; RAS, including KRAS, NRAS, and HRAS mutations; PPARG, PAX8/PPARG gene fusion. ${ }^{a)}$ Mean age. ${ }^{b}$ TBS III, atypia of undetermined significance/follicular lesion of undetermined significance (AUS/FLUS); TBS IV, follicular neoplasm or suspicious for a follicular neoplasm; TBS V, suspicious for malignancy. ${ }^{\text {c}}$ Concurrent Afirma was "suspicious". 
ThyroSeq tubes were sent out as a reflex test for all Bethesda III and IV cases, and for selected Bethesda V cases depending on clinical necessity, regardless of the TI-RADS score. The specimens were sent out for ThyroSeq version 2 (January 1, 2016 to December 31, 2017) or version 3 (January 1, 2018 to April 1, 2018). The presence of any identified genetic alteration was considered a positive test.

\section{Data Analysis and Statistics}

A P-value of $<0.05$ was considered to indicate statistical significance. Continuous variables are presented as mean \pm standard deviation. The correlations between demographics, TI-RADS features and levels, ThyroSeq results (positive vs. negative) and TBSRTC diagnoses with thyroid malignancy as the outcome were analyzed using binary logistic regression and odds ratios (ORs) with 95\% confidence intervals (Cls) (Supplementary Table 1), to study whether the above factors were predictive of malignancy in thyroid nodules. ThyroSeq results of "insufficient" were excluded in the binary logistic regression analysis. The diagnosis of non-invasive follicular thyroid neoplasm with papillary-like nuclear features (NIFTP) on surgical resection pathology was categorized in the malignant category ("thyroid neoplasm") or removed from the malignant category ("thyroid malignancy") for calculation purposes in binary logistic regression analysis (Supplementary Table 1).

To study whether demographics, TI-RADS levels and TBSRTC diagnoses were predictive of ThyroSeq molecular results (positive vs. negative), binary logistic regression analysis was conducted, and ORs with 95\% Cls were calculated (Tables 2, 3).

\section{Results}

Detailed demographic information, nodule size, ACR TI-RADS features and levels, TBSRTC category, and molecular results are summarized in Table 1. Most cases were TR4 nodules (44/81, $54.3 \%$ ) (Table 1), and the most common cytologic diagnoses were TBSRTC III (64/81, 79.0\%) (Table 1). Exemplary ultrasound images, cytopathology and histopathology photomicrography for thyroid nodules are presented in Figs. 2-5.

\section{Molecular Alterations Stratified by TI-RADS Categories}

Molecular alterations were detected in $89.2 \%$ of cases (65/81) (Table 1). RAS mutations were the most common mutation across all TIRADS categories (TR2 2/2, TR3 10/19, TR4 13/44, and TR5 8/16) (Table 1). On surgical pathology follow-up, $45.7 \%$ of thyroid nodules were benign (37/81) (Table 1). NIFTP diagnoses made up $28.4 \%$ of cases (23/81) (Table 1).

The age, sex distribution, cytology category, surgical pathology diagnosis, and molecular testing results for thyroid nodules in reference to the TR scores are summarized in Table 1.

\section{Associations between Ultrasound Features, ThyroSeq Status, and Malignancy}

ThyroSeq results (OR, 6.859; $95 \% \mathrm{Cl}, 1.955$ to $24.061 ; \mathrm{P}=0.003)$

(Supplementary Table 1) were positively correlated with thyroid malignancy when NIFTP was categorized in the malignant category for the outcome (thyroid neoplasm) (Supplementary Table 1), but not when NIFTP was removed from the malignancy category (thyroid malignancy) (Supplementary Table 1). Thyroid neoplasm (including NIFTP) tended to present in younger age groups $(48.19 \pm 14.3$ vs. $53.4 \pm 15.3 ; \mathrm{OR}, 0.967 ; 95 \% \mathrm{Cl}, 0.933$ to $1.003 ; \mathrm{P}=0.071)$ (Supplementary Table 1). Nodule size, sex, cytology category, and TI-RADS levels did not show correlations with the outcome of thyroid neoplasm in surgical resection specimens. When NIFTP was not categorized as a malignant outcome (thyroid malignancy) (Supplementary Table 1), the TI-RADS levels (OR, 2.759; 95\% Cl, 1.149 to $6.622 ; P=0.023$ ) (Supplementary Table 1) were positively correlated with thyroid malignancy. However, nodule size, age, sex, cytology category (TBSRTC III to V), and ThyroSeq results did not

Table 2. Binary logistic regression analyses of the association between clinical and TI-RADS characteristics in correlation with molecular alterations on ThyroSeq

\begin{tabular}{lccc}
\hline & Odds ratio & 95\% Confidence interval & P-value \\
\hline Age & 1.024 & $0.985-1.063$ & 0.229 \\
Nodule size & 0.839 & $0.578-1.216$ & 0.353 \\
Sex & 1.011 & $0.285-3.595$ & 0.986 \\
TI-RADS & 0.308 & $1.458-2.183$ & 0.670 \\
Cytologic diagnosis & 0.670 & $0.308-1.458$ & 0.312 \\
\hline
\end{tabular}

TI-RADS, Thyroid Imaging Reporting and Data System.

Table 3. Binary logistic regression analyses of the association between clinical and sonographic characteristics in correlation with molecular alterations on ThyroSeq

\begin{tabular}{lccc}
\hline & Odds ratio & 95\% Confidence interval & P-value \\
\hline Age & 1.037 & $0.994-1.081$ & 0.091 \\
Nodule size & 0.919 & $0.586-1.443$ & 0.715 \\
Sex & 0.670 & $0.160-2.809$ & 0.584 \\
Cytologic diagnosis & 1.458 & $0.515-4.128$ & 0.477 \\
Composition & 2.913 & $0.590-14.383$ & 0.190 \\
Echogenicity & 0.162 & $0.048-0.545$ & $0.003^{*}$ \\
Shape & 1.062 & $0.469-2.406$ & 0.885 \\
Margin & 1.383 & $0.496-3.860$ & 0.535 \\
Echogenic foci & 0.725 & $0.412-1.277$ & 0.266 \\
\hline
\end{tabular}

${ }^{*} P<0.05$, binary logistic regression. 

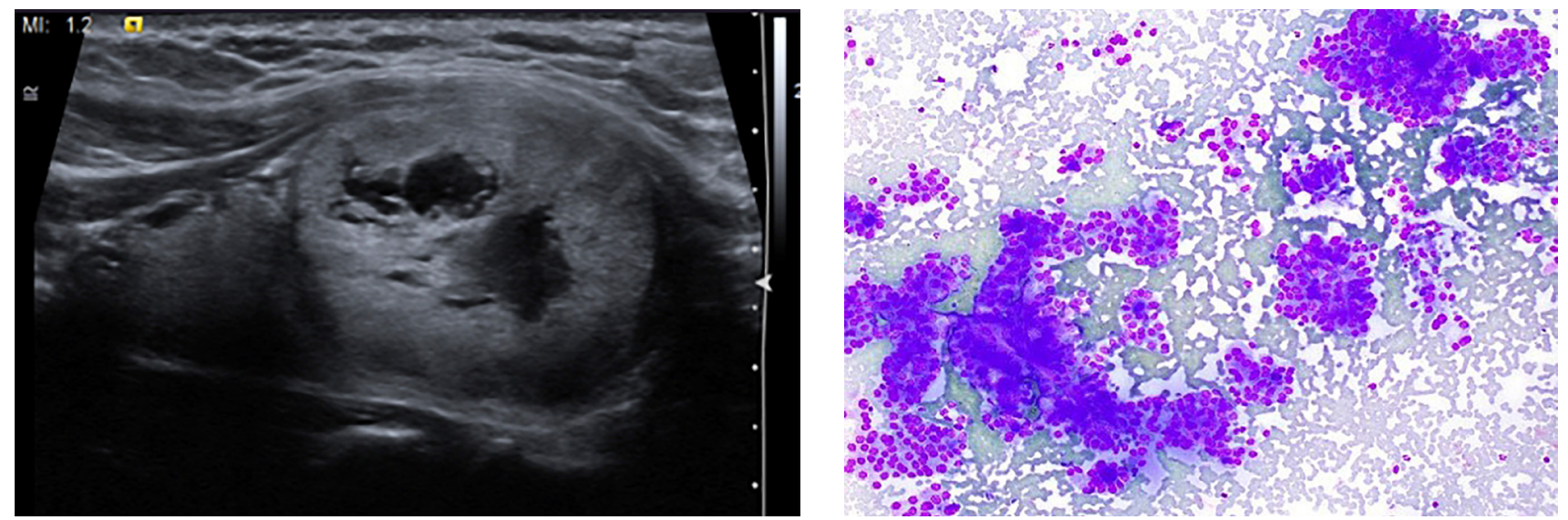

A

B
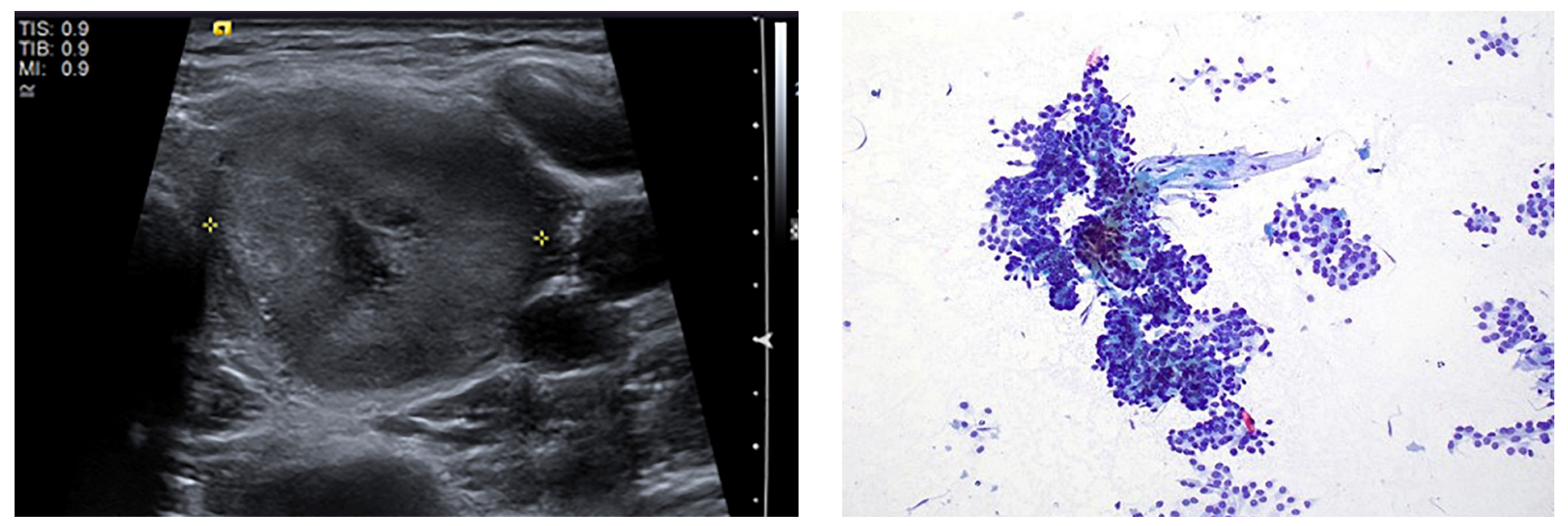

C

D

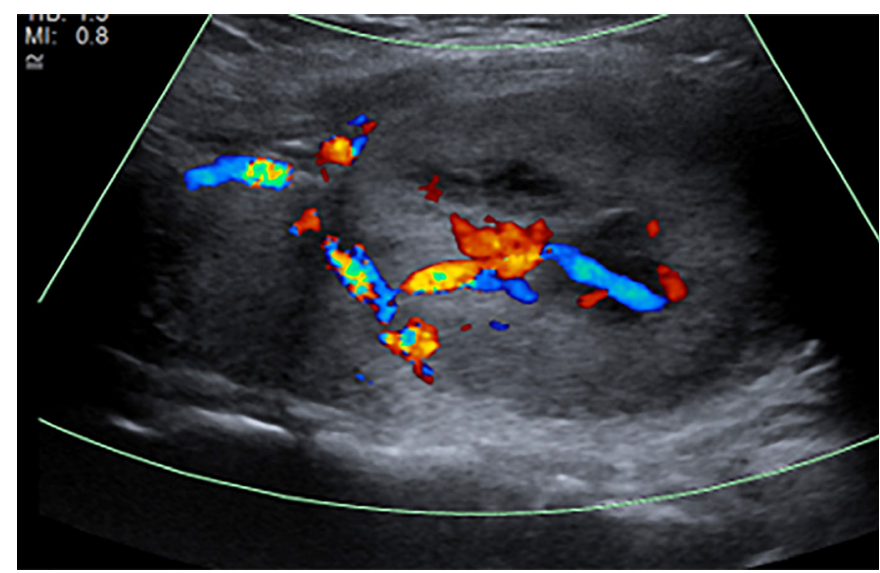

E

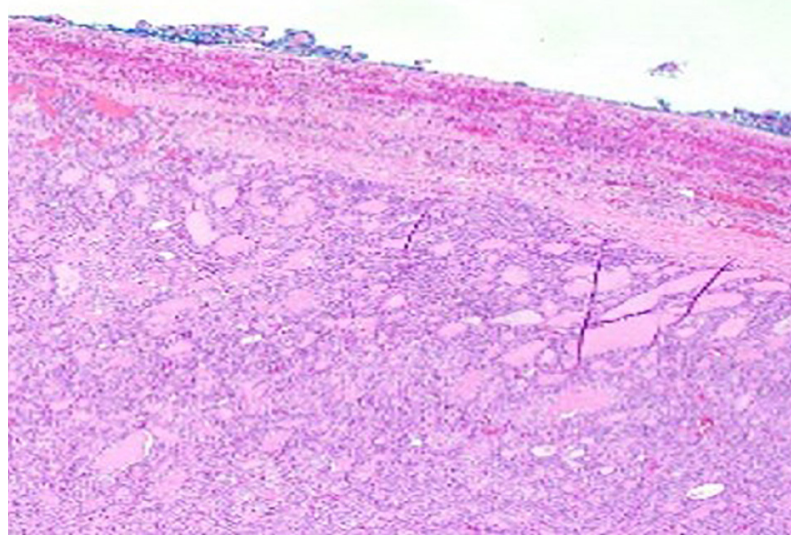

$\mathrm{F}$

Fig. 2. Exemplary ultrasonography, cytopathology and histopathology photomicrography for TI-RADS TR2 nodule.

This nodule was a mixed cystic and solid, isoechoic and focal hypoechoic, well-circumscribed hypervascular thyroid nodule (TI-RADS TR2) $(A, C, E)$, which exhibited architectural atypia (macrofollicles and microfollicles) and cytologic atypia (nuclear crowding and enlargement) on cytopathology (TBSRTC III, AUS; B, Diff-Quik stain, $\times 400$; D, Papanicolaou stain, $\times 400$ ) with a HRAS mutation and was confirmed to be nodular hyperplasia $(F, H \& E$ stain, $\times 100)$ on surgical resection.TI-RADS, Thyroid Imaging Reporting and Data System; TBSRTC, The Bethesda System for Reporting Thyroid Cytopathology; AUS, atypia of undetermined significance. 


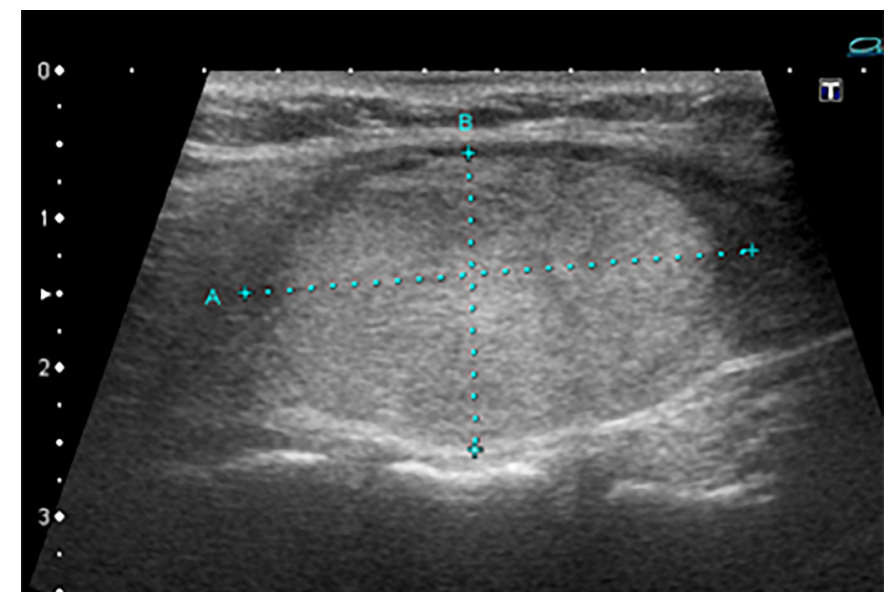

A

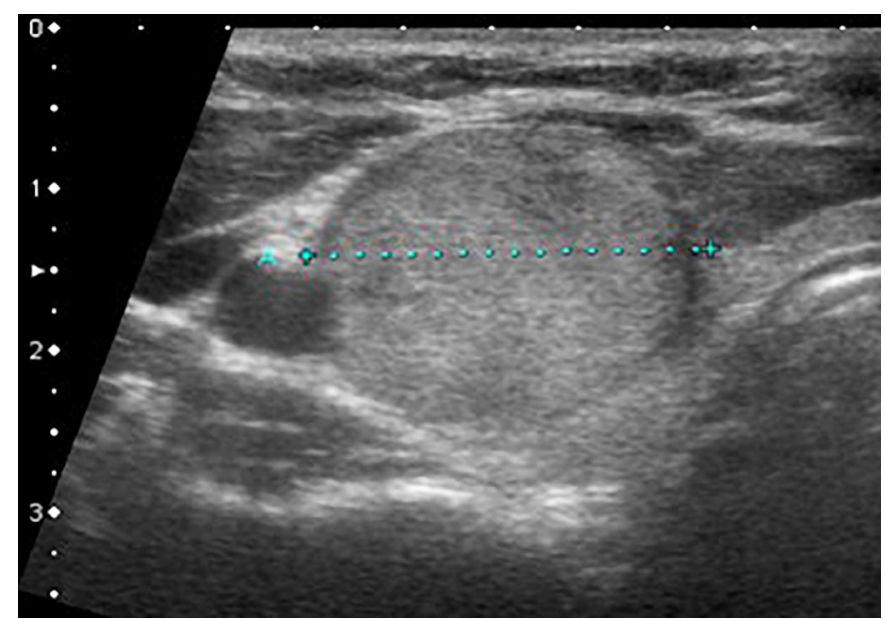

C

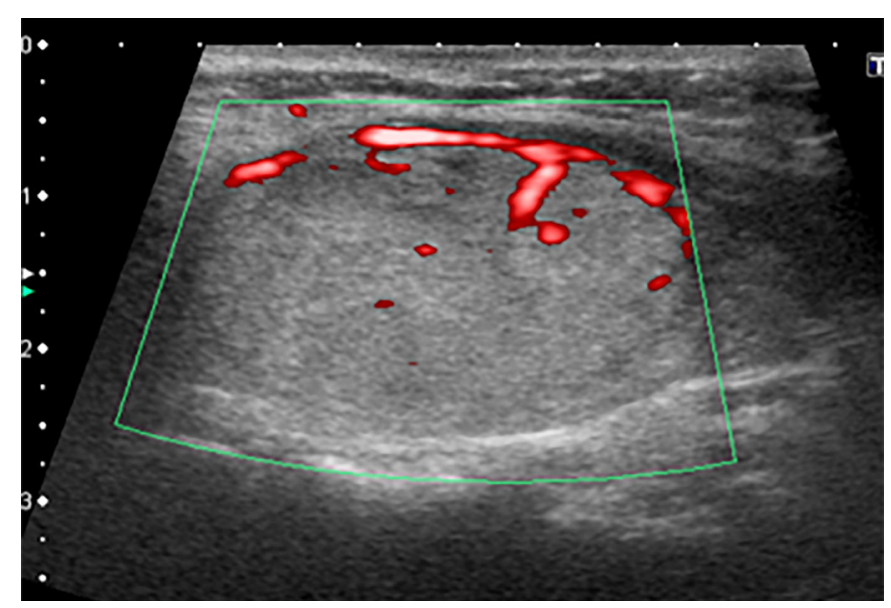

$\mathrm{E}$

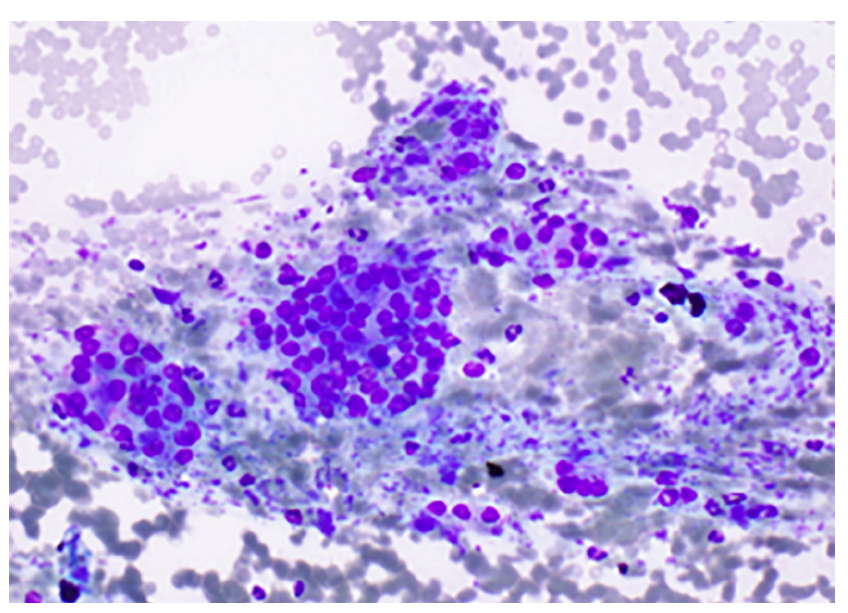

B

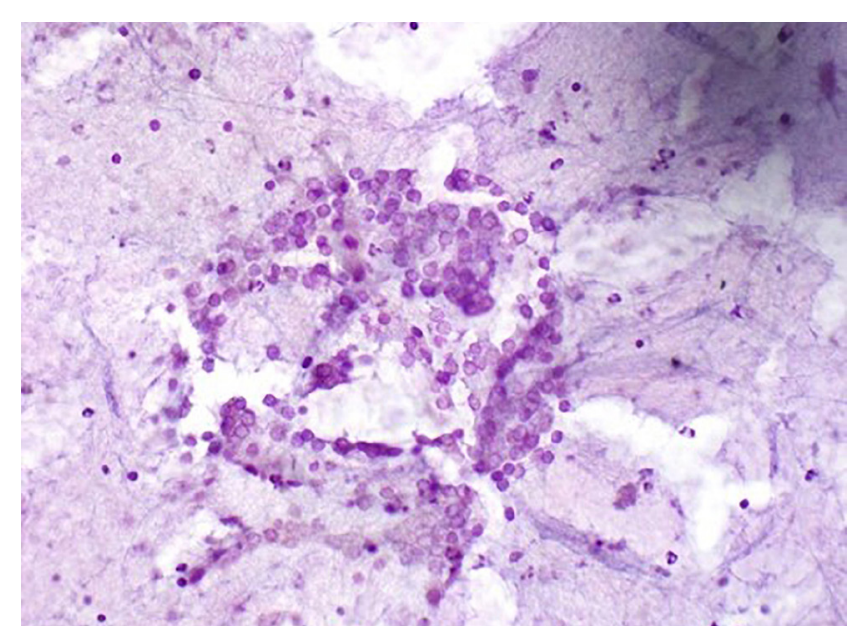

D

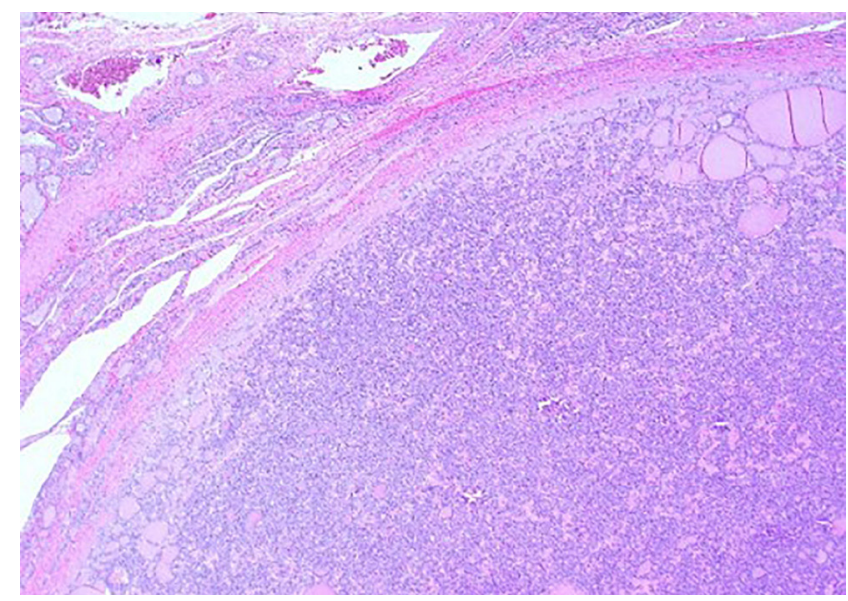

$\mathrm{F}$

Fig. 3. Exemplary ultrasonography, cytopathology and histopathology photomicrography for TI-RADS TR3 nodule.

This is a solid hyperechoic thyroid nodule (TI-RADS TR3) (A, C, E), which exhibited architectural atypia (macrofollicles and microfollicles) and cytologic atypia (nuclear crowding and enlargement) on cytopathology (TBSRTC III, AUS; B, Diff-Quik stain, $\times 400$; D, Papanicolaou stain, $\times 400$ ) with a HRAS mutation and was confirmed to be a follicular adenoma (F, H\&E stain, $\times 100)$ on surgical resection. TI-RADS, Thyroid Imaging Reporting and Data System; TBSRTC, The Bethesda System for Reporting Thyroid Cytopathology; AUS, atypia of undetermined significance. 


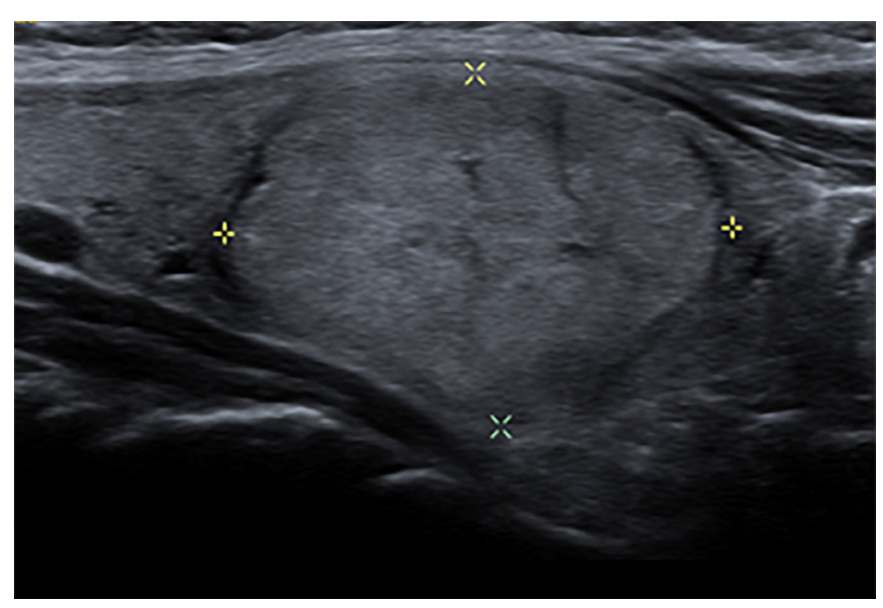

A

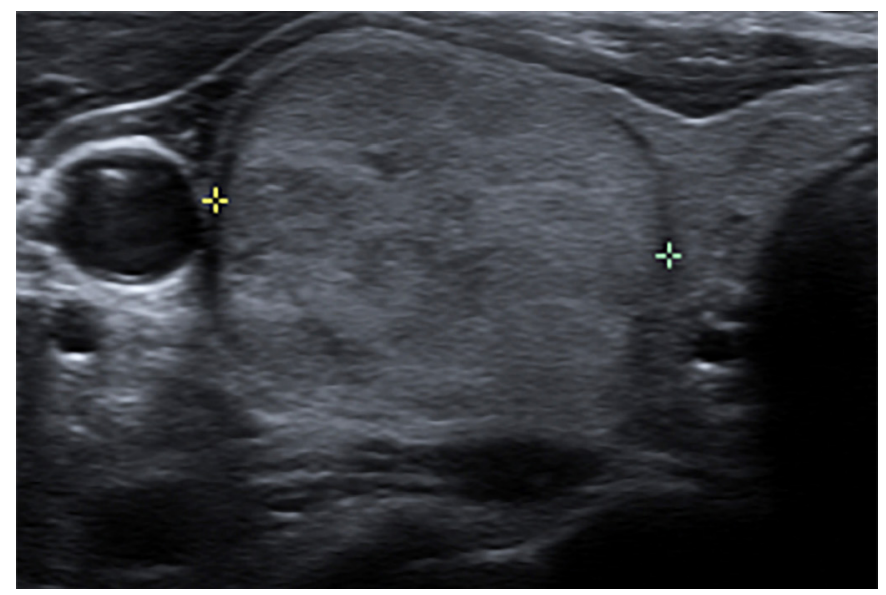

C

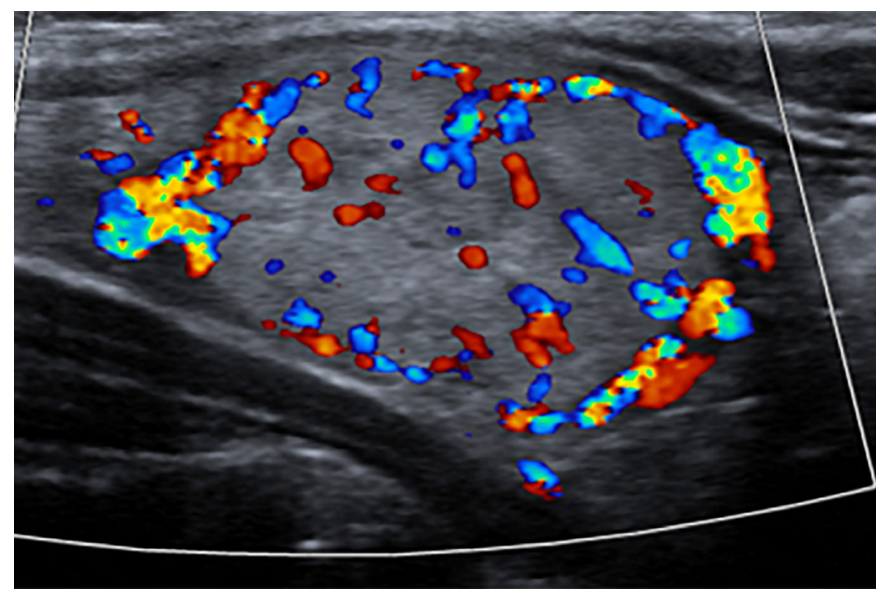

E

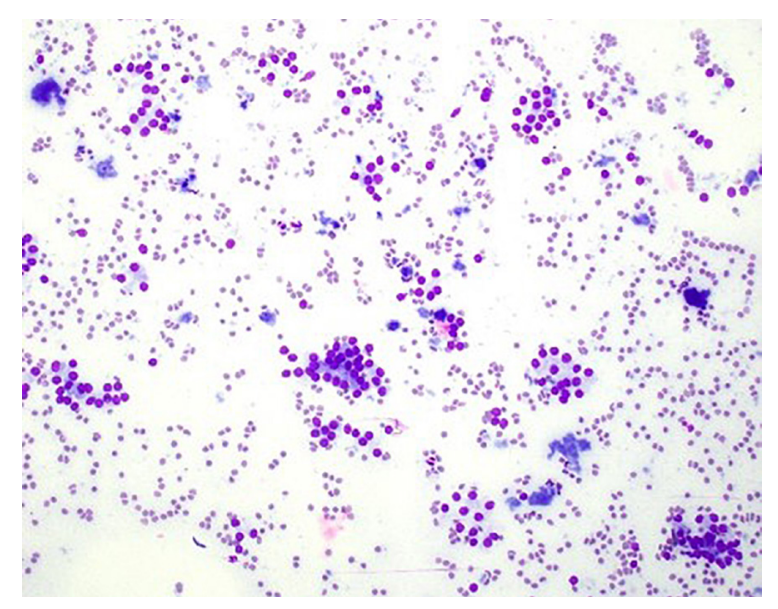

B

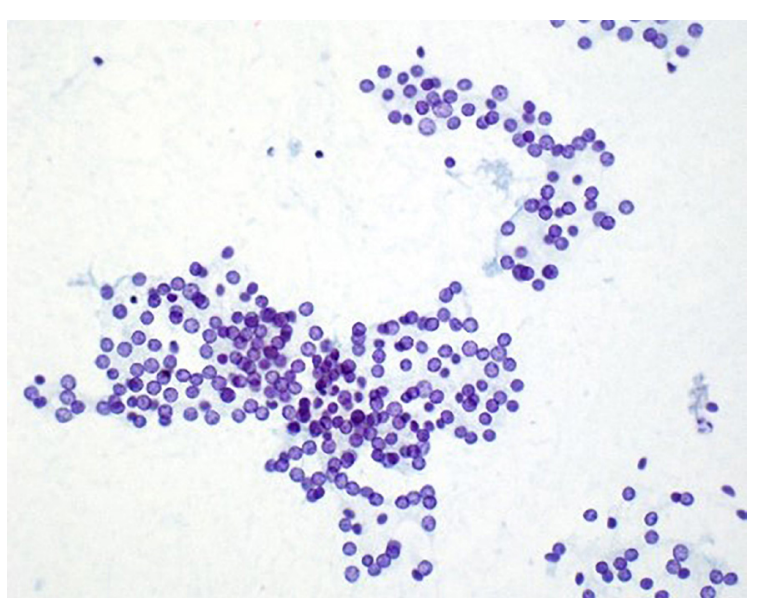

D

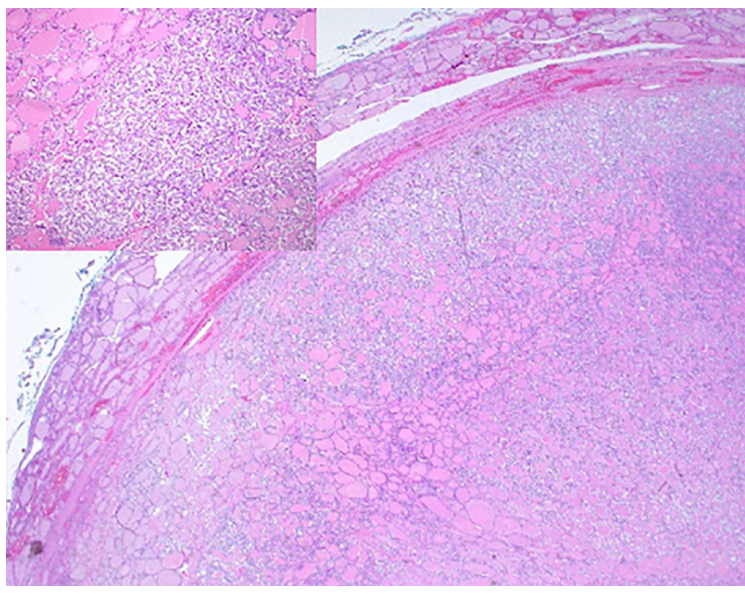

$\mathrm{F}$

Fig. 4. Exemplary ultrasonography, cytopathology and histopathology photomicrography for TI-RADS TR4 nodule.

The nodule is a solid, isoechoic, lobulated thyroid nodule (TI-RADS TR4) (A, C, E) which exhibited cell crowding, microfollicles and dispersed isolated cells on cytopathology (TBSRTC IV, suspicious for follicular neoplasm; B, Diff-Quik stain, $\times 400$; D, Papanicolaou stain, $\times 400$ ) with a TERT mutation and was confirmed to be a follicular carcinoma ( $F$, H\&E stain, $\times 100$; inset, extracapsular invasion, $\times 200$ ) on surgical resection. TI-RADS, Thyroid Imaging Reporting and Data System; TBSRTC, The Bethesda System for Reporting Thyroid Cytopathology. 


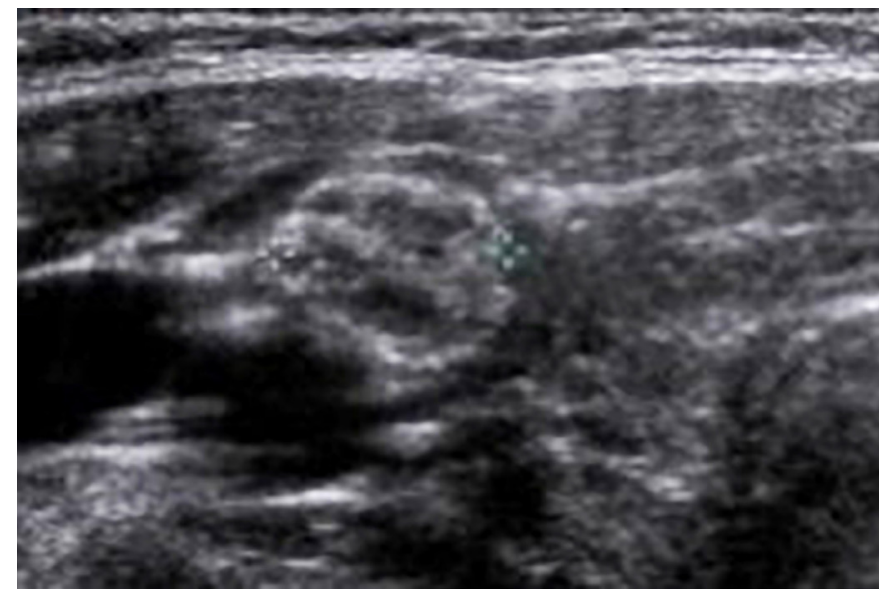

A

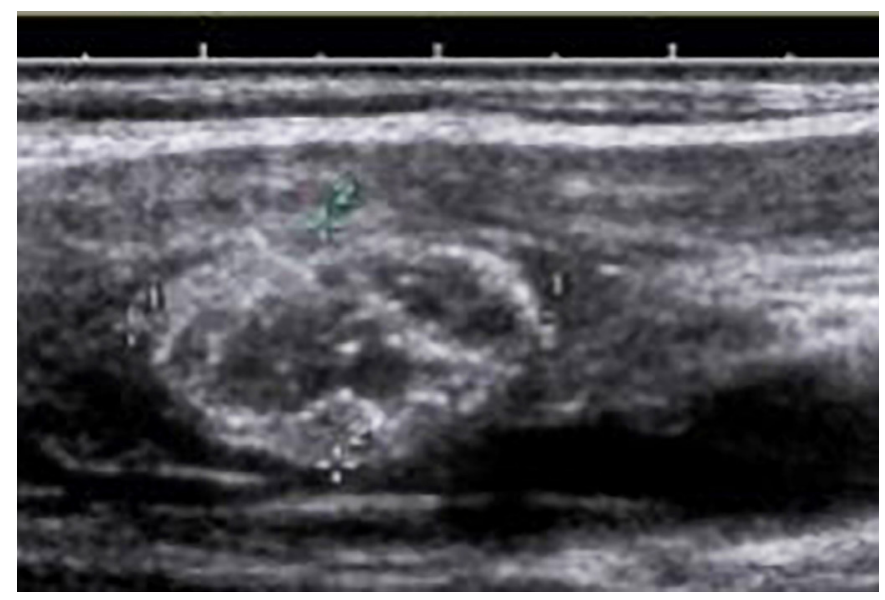

C

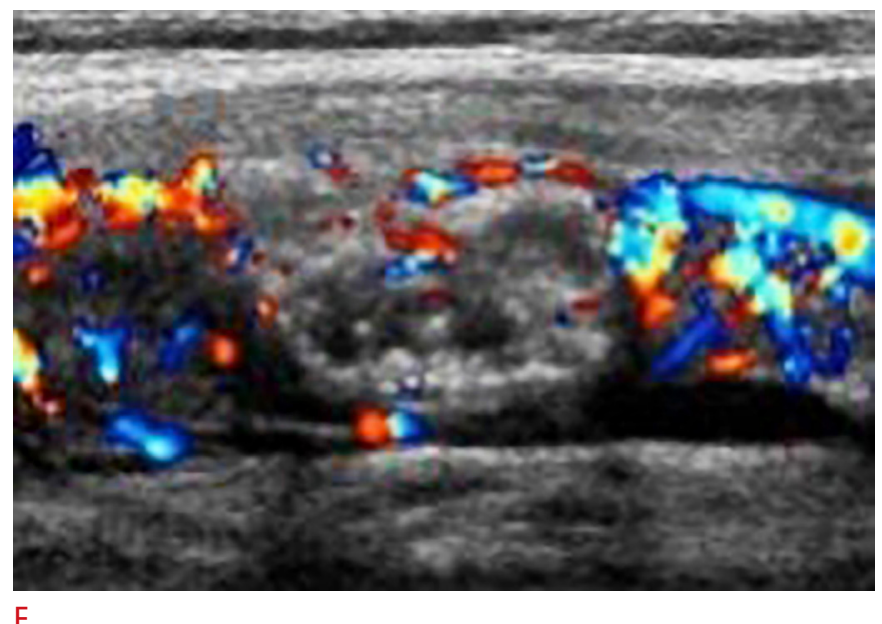

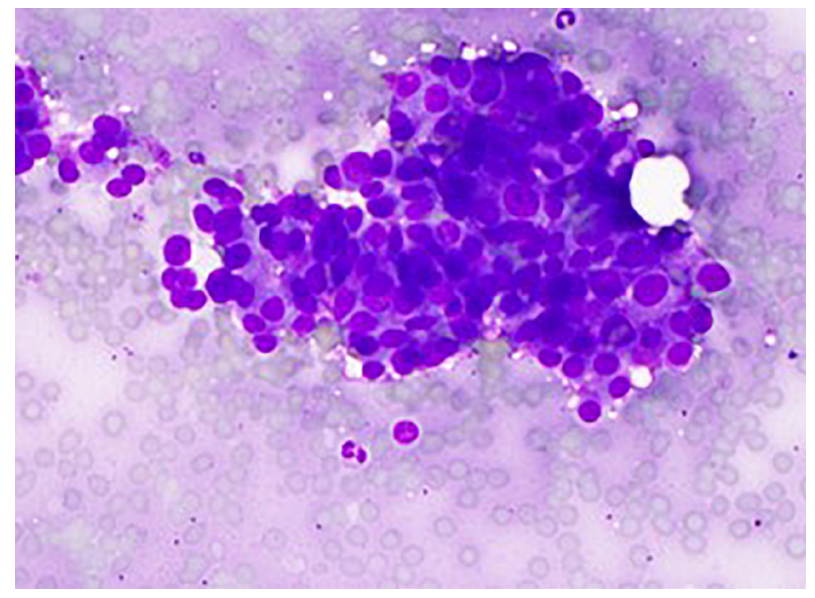

B

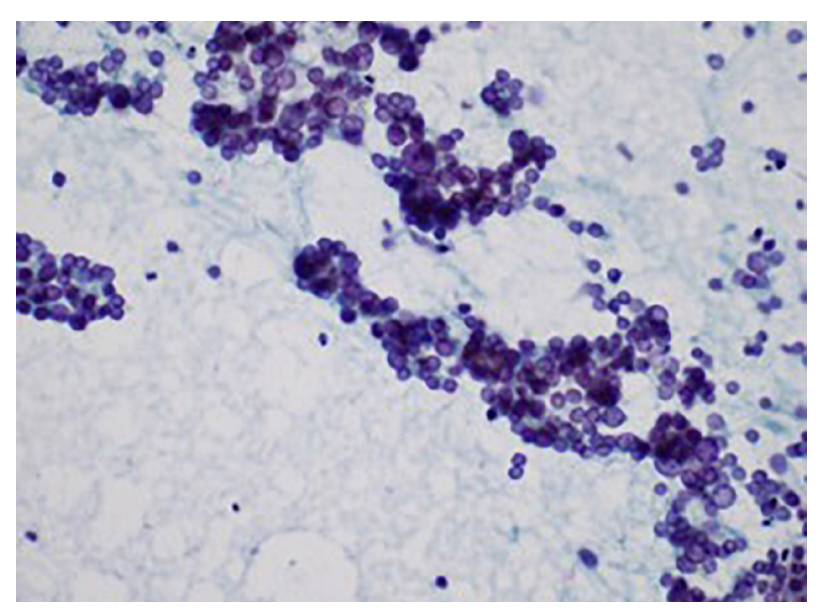

D

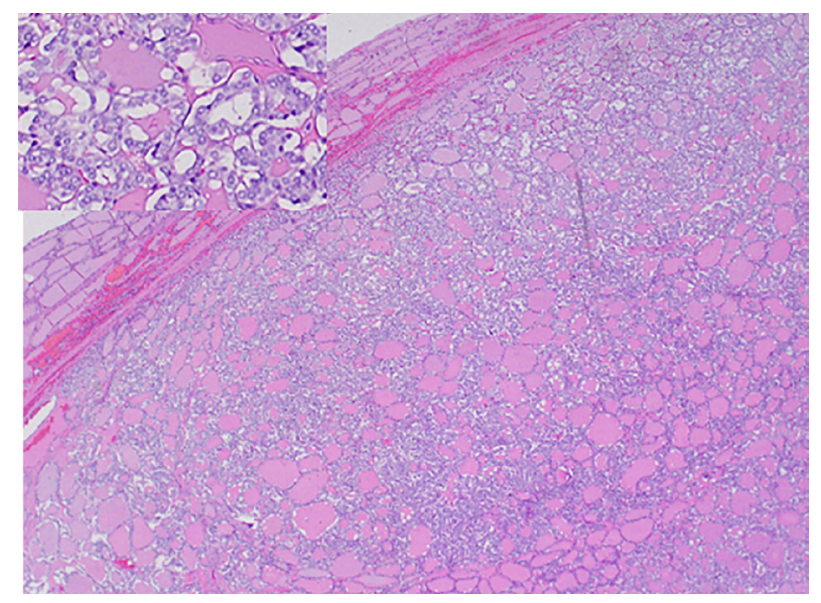

$\mathrm{F}$

Fig. 5. Exemplary ultrasonography, cytopathology and histopathology photomicrography for TI-RADS TR5 nodule.

The nodule is an almost solid, hypoechoic thyroid nodule with punctate echogenic foci (TI-RADS TR5) (A, C, E), which exhibit cell crowding, microfollicles, and dispersed isolated cells with nuclear enlargement, nuclear pallor, nuclear grooves on cytopathology (TBSRTC $V$, suspicious for follicular neoplasm; B, Diff-Quik stain, $\times 400$; D, Papanicolaou stain, $\times 400$ ) on cytopathology with a negative ThyroSeq result and was confirmed to be a classic papillary thyroid carcinoma (F, H\&E stain, $\times 100$; inset, $\times 200$ ) on surgical resection. TI-RADS, Thyroid Imaging Reporting and Data System; TBSRTC, The Bethesda System for Reporting Thyroid Cytopathology. 
show a statistically significant correlation with a malignant outcome in surgical resection specimens (Supplementary Table 1).

\section{Associations between Ultrasound Features and ThyroSeq Status}

Demographic characteristics, nodule size, TI-RADS levels, and TBSRTC diagnoses did not show correlations with positive ThyroSeq results (genetic alterations) (Table 2). When the ultrasound features (composition, echogenicity, shape, margins, and the presence of echogenic foci) composing the TI-RADS levels were analyzed in correlation with ThyroSeq results as the outcome (Table 3), echogenicity scores were found to be negatively correlated with ThyroSeq results in thyroid nodules $(\mathrm{OR}, 0.162 ; 95 \% \mathrm{Cl}, 0.048$ to $0.545 ; \mathrm{P}<0.01$ ) (Table 3 ). Among the 23 hyperechoic or isoechoic nodules (echogenicity score of 1: 23/81, 28.4\%) (Table 4), 21 showed genetic alterations on ThyroSeq (21/23, 91.3\%) (Table 4), most commonly RAS mutations (13/21, 61.9\%) (Table 4). Most of the hyperechoic or isoechoic nodules were TI-RADS TR3 nodules $(15 / 23,65.2 \%)$ (Table 4), and classified as TBSRTC category III on cytology $(16 / 23,69.6 \%)$ (Table 4). Follow-up surgical resection for these cases showed a rate of malignancy (ROM) of $69.6 \%$ in the thyroid neoplasm category (16/23) (Table 4 ) and $26.1 \%$ in the thyroid malignancy category (6/23) (Table 4). Hypoechoic nodules (echogenicity score of 2) were the most common (51/81, 63.0\%) (Table 4). Genetic alterations were detected in 37 hypoechoic nodules (37/51, 71.5\%) (Table 4). The majority of the hypoechoic nodules were TI-RADS TR4 (33/51, 64.7\%) (Table 4), and TBSTRC III (35/51, 68.6\%) (Table 4). Follow-up surgical pathology showed a ROM of $52.9 \%$ in the thyroid neoplasm category (27/51) (Table 4) and $23.5 \%$ in the thyroid malignancy category (12/31) (Table 4). The least common were very hypoechoic nodules (echogenicity score of 3: 7/81, 8.6\%) (Table 4). Genetic alterations were detected in three of the seven very hypoechoic nodules, including one MET mutation, one RAS mutation, and one TERT mutation. The majority of the very hypoechoic nodules were TI-RADS TR4 (5/7, 71.4\%) (Table 4), and TBSTRC III (4/7, 57.1\%) (Table 4). Follow-up surgical pathology showed a ROM of $14.3 \%$ in both the thyroid neoplasm and thyroid malignancy categories (Table 4). Despite a higher rate of alterations detected in thyroid nodules with lower echogenicity scores (hyperechoic/isoechoic group), the majority of the nodules displayed RAS mutation in both the hyperechoic/isoechoic nodules (61.9\%) and hypoechoic nodules (51.4\%) (Table 4).

Age, sex, nodule size, and other sonographic features (composition, shape, margin, and echogenic foci) did not show correlations with ThyroSeq status in the binary logistic regression analyses (Table 3).

\section{Discussion}

Thyroid nodules are generally evaluated with the ACR TI-RADS in combination with cytologic findings and molecular studies for risk stratification and triage $[24,25]$. ACR TI-RADS levels have been shown to correlate with TBSRTC [8] and ROM [26]. Cytologically indeterminate thyroid nodules may pose diagnostic challenges. Therefore, molecular studies have been utilized for therapeutic triage of these cases and are of excellent clinical efficacy with a high negative predictive value $(92 \%-96 \%)[13,14,23]$. Our study aimed to examine the molecular profiles of thyroid nodules stratified by TIRADS categories.

NIFTP is considered an indolent thyroid neoplasm with excellent long-term survival. Though it is agreed that NIFTP cannot be definitively diagnosed preoperatively and is a surgical entity, the categorization of NIFTP remains an area of debate. Therefore, in

Table 4. ThyroSeq results, TI-RADS levels, cytopathology categories, and surgical pathology outcomes in different echogenicity groups

\begin{tabular}{|c|c|c|c|c|c|c|c|c|c|c|c|c|}
\hline \multirow[b]{2}{*}{$\begin{array}{l}\text { Echogenicity } \\
\text { scores }\end{array}$} & \multirow[b]{2}{*}{ Count } & \multirow{2}{*}{$\begin{array}{l}\text { ThyroSeq } \\
\text { positive }\end{array}$} & \multirow[b]{2}{*}{ Common alterations } & \multicolumn{4}{|c|}{ TI-RADS } & \multicolumn{3}{|c|}{ TBSRTC } & \multicolumn{2}{|c|}{ Surgical pathology } \\
\hline & & & & TR2 & TR3 & TR4 & TR5 & III & IV & VI & $\begin{array}{c}\text { Thyroid } \\
\text { neoplasm }^{\text {a) }}\end{array}$ & $\begin{array}{c}\text { Thyroid } \\
\text { malignancy }^{\text {a) }}\end{array}$ \\
\hline $\begin{array}{l}\text { Hyperechoic or } \\
\text { isoechoic } 1\end{array}$ & 23 & $\begin{array}{c}21 \\
(91.3)\end{array}$ & $\begin{array}{l}\text { RAS }^{\mathrm{b})}: 13 \text { (61.9), EIF1AX: } 2 \text { (9.5), NTRK1/3: } \\
1 \text { (4.8), BRAF } F^{\mathrm{V} \text { V00E }}: 1 \text { (4.8), DICER1: } 1 \text { (4.8), } \\
\text { ALK: } 1 \text { (4.8), PPARG: } 1 \text { (4.8), TSHR: } 1 \text { (4.8), }\end{array}$ & $\begin{array}{c}2 \\
(8.7)\end{array}$ & $\begin{array}{c}15 \\
(65.2)\end{array}$ & $\begin{array}{c}6 \\
(26.1)\end{array}$ & 0 & $\begin{array}{c}16 \\
(69.6)\end{array}$ & $\begin{array}{c}6 \\
(26.1)\end{array}$ & $\begin{array}{c}1 \\
(4.3)\end{array}$ & $\begin{array}{c}16 \\
(69.6)\end{array}$ & $\begin{array}{c}6 \\
(26.1)\end{array}$ \\
\hline Hypoechoic 2 & 51 & $\begin{array}{c}37 \\
(72.5)\end{array}$ & $\begin{array}{c}\text { RAS }^{\text {b) }}: 19 \text { (51.4), PPARG: } 5 \text { (13.5), P53: } \\
4 \text { (10.8), BRAF }{ }^{\text {K601E. }}: 2 \text { (5.4), MET: } 2 \text { (5.4), } \\
\text { TERT: } 1 \text { (2.7), NTRK1/3: } 1 \text { (2.7), IGF2BP3: } \\
1 \text { (2.7), GEP-P: } 2 \text { (5.4) }\end{array}$ & 0 & $\begin{array}{c}4 \\
(7.8)\end{array}$ & $\begin{array}{c}33 \\
(64.7)\end{array}$ & $\begin{array}{c}14 \\
(27.5)\end{array}$ & $\begin{array}{c}35 \\
(68.6)\end{array}$ & $\begin{array}{c}13 \\
(25.5)\end{array}$ & $\begin{array}{c}3 \\
(5.8)\end{array}$ & $\begin{array}{c}27 \\
(52.9)\end{array}$ & $\begin{array}{c}12 \\
(23.5)\end{array}$ \\
\hline $\begin{array}{l}\text { Very } \\
\text { hypoechoic } 3\end{array}$ & 7 & $\begin{array}{c}3 \\
(42.9)\end{array}$ & $\begin{array}{c}\text { MET: } 1 / 3(33.3 \%), R^{\text {b }} \text { (b): } 1 / 3(33.3 \%) \\
\text { TERT: } 1 / 3(33.3 \%)\end{array}$ & 0 & 0 & $\begin{array}{c}5 \\
(71.4)\end{array}$ & $\begin{array}{c}2 \\
(28.6)\end{array}$ & $\begin{array}{c}3 \\
(42.9)\end{array}$ & $\begin{array}{c}4 \\
(57.1)\end{array}$ & 0 & $\begin{array}{c}1 \\
(14.3)\end{array}$ & $\begin{array}{c}1 \\
(14.3)\end{array}$ \\
\hline
\end{tabular}

Values are presented as number (\%).

TI-RADS, Thyroid Imaging Reporting and Data System; TBSRTC, The Bethesda System for Reporting Thyroid Cytopathology; GEP-P, genetic expression profile positive.

${ }^{a}$ Thyroid neoplasm: non-invasive follicular thyroid neoplasm with papillary-like nuclear features (NIFTP) was included in this category; thyroid malignancy: NIFTP was excluded from this category. ${ }^{\text {b) }}$ RAS, including KRAS, NRAS, and HRAS mutations; PPARG, PAX8/PPARG gene fusion. 
this study, NIFTP was classified within and then removed from the malignancy category. When NIFTP was removed from the malignancy category, the TI-RADS scores positively correlated with malignancy. Whereas, when NIFTP was classified in the malignant category, the TI-RADS scores did not show a significant correlation with malignancy. This is perhaps unsurprising since NIFTP has been shown to lack the ultrasound features typically associated with classic PTC (e.g., microcalcifications, taller-thanwide shape, and irregular margins), which result in higher TI-RADS scores when present [27]. The predominant ultrasound features of NIFTP have been described as solid, hypoechoic, wider than tall, a circumscribed margin, no calcifications, and intermediate suspicion on ultrasonography [27]. These features may explain why TI-RADS levels only showed a positive correlation with thyroid malignancy when NIFTP was removed from (and thus no longer diluted) the malignancy category, as NIFTPs usually exhibit lower TI-RADS levels, similar to benign thyroid nodules $[27,28]$. However, as NIFTP nodules are usually solid, similar to malignant nodules, the individual feature of the composition score tended to be positively correlated to the thyroid neoplasm outcome when NIFTP was grouped in the malignancy category [28].

Molecular alterations occur not only in malignant nodules, but also frequently in neoplastic nodules such as NIFTP and even some benign thyroid lesions $[29,30]$. However, the significance of clonal genetic alterations observed in histologically benign nodules is relatively unclear. In our study, ThyroSeq showed a positive correlation with thyroid malignancy when NIFTP was categorized in the malignancy category (thyroid neoplasm). When NIFTP was removed from the malignant category (thyroid malignancy), the non-malignant category showed an increase in the number of neoplastic cases with molecular alterations; thus, no correlation was detected between ThyroSeq and malignancy. In our dataset, the most common mutations across all TI-RADS categories were RAS mutations, which occurred in both malignancies and NIFTP $[29,31]$. Only the TR4 and TR5 categories displayed more aggressive mutations such as BRAF ${ }^{\mathrm{V} 600 \mathrm{E}}$ and TERT.

Although the presence of a high TI-RADS score generally increased the likelihood of detecting a genetic alteration in ThyroSeq, the association was not statistically significant, which is consistent with previous studies [32]. Because ThyroSeq is generally only performed on cytologically indeterminate thyroid nodules, thyroid nodules with malignant diagnoses (e.g., classic PTC) that stratified in the higher TI-RADS categories were excluded from this study simply because they did not have an associated ThyroSeq test result. It is possible that statistical significance could have been achieved had molecular testing been performed on TBSTRC VI cases, thereby increasing our sample size and presumably increasing the number of aggressive (BRAF-like) alterations stratified in the higher TI-RADS categories. Thus, the ability to predominantly examine cytologically indeterminate nodules due to a lack of ThyroSeq testing in other categories is an inherent limitation in our study. Moreover, only cases with in-house surgical resection were included, which introduced selection bias, as the majority of benign cases could not be included in this study set due to the lack of necessity of surgical management.

Interestingly, in this study, low echogenicity scores (hyperechogenicity or isoechogenicity) correlated with a higher possibility of molecular alterations in the thyroid nodules (Tables 3, 4). The echogenicity of tissue refers to the ability to reflect or transmit ultrasound waves in the context of surrounding tissues, and a visible difference in contrast will be apparent on the screen when there is an interface of structures with different echogenicities [33]. Generally, hyperechoic or isoechoic nodules are considered as sonographically "benign" nodules, and the TR score can be as low as 1 point for these nodules [2]. Despite a higher rate of alterations detected in the hyperechoic/ isoechoic group, the majority of the nodules displayed RAS mutations in both the hyperechoic/isoechoic and hypoechoic groups. It is surprising to see that hypoechoic nodules did not show a higher rate of molecular alterations than hyperechoic/isoechoic nodules, as a number of studies have shown that malignant nodules more often display hypoechoic echogenicity [34,35]. However, it is hypothesized that while malignant nodules typically display a hypoechoic pattern on ultrasound, the reverse is not always true-hypoechoic nodules alone, without other concerning ultrasound features, do not necessarily indicate molecular alterations or malignancy associated with a thyroid nodule. It would be interesting to build upon these findings in a larger-scale prospective study.

Echogenicity itself is a feature used to evaluate thyroid nodules that should be considered in concert with other sonographic features. $\mathrm{Na}$ et al. [36] found that the malignancy risk of markedly and mildly hypoechoic nodules with any suspicious ultrasound feature (microcalcification, taller-than-wide shape, spiculated/ microlobulated margin) was very high, whereas the malignancy risk of markedly and mildly hypoechoic nodules without suspicious ultrasound features was only intermediate in the group of solid hypoechoic nodules. Moreover, microcalcification and spiculated/ microlobulated margins were independently predictive of malignancy in even the isoechoic and hyperechoic nodule group [36]. In the present study, RAS mutations were the most common genetic alteration in hyperechoic or isoechoic nodules, followed by EIF1AX mutations, both of which are relatively low-risk mutations. One hyperechoic or isoechoic nodule carried a BRAF ${ }^{\mathrm{V} 600 \mathrm{E}}$ mutation. This nodule also showed punctate echogenic foci and a lobulated/ irregular margin, with a TI-RADS level of TR4. Additionally, as a 
single-center study, there may also have been sampling limitations. For example, there were only two TR2 cases, since FNA biopsies are usually not performed on TI-RADS TR1 and TR2 nodules. Both TR2 nodules were hyperechoic-or-isoechoic for echogenicity, showed cytologic atypia on FNA (TBSRTC III and IV, respectively), and a follow-up with ThyroSeq testing exhibited RAS mutations. Due to the limited sample size of TR2 nodules, this study could not demonstrate the spectrum of molecular features of low TI-RADS nodules with low echogenicity scores.

The present study is limited in that only cytologically indeterminate thyroid nodules were included, as only TBSRTC class III, IV and V specimens underwent further molecular studies according to the current protocol. Therefore, the cytological classification did not show statistical significance in correlation with surgical pathology outcomes in this study set, as TBSRTC class III and IV specimens show similar ROM [10]. For similar reasons, TI-RADS scores did not show statistical significance in correlation with surgical pathology outcomes. Ultrasound studies with TI-RADS scores, however, aid in identifying thyroid nodules that require FNA cytology assessment with molecular tests for further risk stratification of indeterminate thyroid nodules.

The rate of NIFTP was high in our study group. This may be caused by the selection bias mentioned above, as cytological indeterminate thyroid nodules are triaged first with ThyroSeq study, and surgical resection is usually performed when a genetic alteration is identified by ThyroSeq evaluation. Therefore, surgery may be performed more often on nodules with low-risk features on radiology and cytology when ThyroSeq results are positive. Moreover, NIFTP is a relatively common diagnosis in thyroid resection specimens at the authors' institution [37].

In conclusion, this study analyzed the ultrasound features composing the TI-RADS levels in correlation with thyroid malignancy (including and excluding NIFTP) and genetic alterations in thyroid nodules. Higher-risk molecular alterations tended to stratify with the higher TI-RADS categories; only TR4 and TR5 categories displayed more aggressive mutations such as BRAF ${ }^{\mathrm{V} 600 \mathrm{E}}$ and TERT. However, some alterations presented in benign, neoplastic, and malignant entities (e.g., RAS alterations) and did not stratify with any TI-RADS category in particular. While echogenicity scores were found to be negatively correlated with genetic alterations in thyroid nodules, other sonographic features and cytological features should be considered together in the evaluation of the biological behavior of thyroid nodules.

ORCID: Rong Xia: https://orcid.org/0000-0001-8573-2152; Wei Sun: https://orcid.org/00000002-4404-9733; Joseph Yee: https://orcid.org/0000-0002-1088-0035; Sheila Sheth: https:// orcid.org/0000-0001-7698-8519; Chrystia Slywotzky: https://orcid.org/0000-0003-43402029; Tamar C. Brandler: https://orcid.org/0000-0001-8272-9900

\section{Author Contributions}

Conceptualization: Xia R, Sun W, Yee J, Sheth S, Slywotzky C, Hodak S, Brandler TC. Data acquisition: Xia R, Sun W, Yee J. Data analysis or interpretation: Sun W. Drafting of the manuscript: Brandler TC. Critical revision of the manuscript: Xia R, Sun W, Yee J, Sheth $S$, Slywotzky C, Hodak S, Brandler TC. Approval of the final version of the manuscript: all authors.

\section{Conflict of Interest}

No potential conflict of interest relevant to this article was reported.

\section{Supplementary Material}

Supplementary Table 1. Binary logistic regression analyses of the association between clinical and TI-RADS characteristics in correlation with outcome of thyroid carcinoma (https://doi.org/10.14366/ usg.21130).

\section{References}

1. Ferlay J, Soerjomataram I, Dikshit R, Eser S, Mathers C, Rebelo $M$, et al. Cancer incidence and mortality worldwide: sources, methods and major patterns in GLOBOCAN 2012. Int J Cancer 2015;136:E359-E386.

2. Tessler FN, Middleton WD, Grant EG, Hoang JK, Berland LL, Teefey SA, et al. ACR Thyroid Imaging, Reporting and Data System (TIRADS): White Paper of the ACR TI-RADS Committee. J Am Coll Radiol 2017;14:587-595.

3. Yan KL, Li S, Tseng CH, Kim J, Nguyen DT, Dawood NB, et al. Rising incidence and incidence-based mortality of thyroid cancer in California, 2000-2017. J Clin Endocrinol Metab 2020;105:dgaa121.

4. Kitahara CM, Sosa JA. Understanding the ever-changing incidence of thyroid cancer. Nat Rev Endocrinol 2020;16:617-618.

5. Gitto S, Grassi G, De Angelis C, Monaco CG, Sdao S, Sardanelli $F$, et al. A computer-aided diagnosis system for the assessment and characterization of low-to-high suspicion thyroid nodules on ultrasound. Radiol Med 2019;124:118-125.

6. Delfim RLC, Veiga L, Vidal AP, Lopes F, Vaisman M, Teixeira P. Likelihood of malignancy in thyroid nodules according to a proposed Thyroid Imaging Reporting and Data System (TI-RADS) classification merging suspicious and benign ultrasound features. Arch Endocrinol Metab 2017;61:211-221.

7. Gao LY, Wang Y, Jiang YX, Yang $X$, Liu RY, Xi XH, et al. Ultrasound is helpful to differentiate Bethesda class III thyroid nodules: a PRISMA-compliant systematic review and meta-analysis. Medicine (Baltimore) 2017;96:e6564.

8. Vargas-Uricoechea H, Meza-Cabrera I, Herrera-Chaparro J. Concordance between the TIRADS ultrasound criteria and the BETHESDA cytology criteria on the nontoxic thyroid nodule. Thyroid Res 2017;10:1. 
9. Rahal AJ, Falsarella PM, Rocha RD, Lima JP, Iani MJ, Vieira FA, et al. Correlation of Thyroid Imaging Reporting and Data System [TIRADS] and fine needle aspiration: experience in 1,000 nodules. Einstein (Sao Paulo) 2016;14:119-123.

10. Cibas ES, Ali SZ. The 2017 Bethesda System for Reporting Thyroid Cytopathology. Thyroid 2017;27:1341-1346.

11. Mathur A, Weng J, Moses W, Steinberg SM, Rahbari R, Kitano $M$, et al. A prospective study evaluating the accuracy of using combined clinical factors and candidate diagnostic markers to refine the accuracy of thyroid fine needle aspiration biopsy. Surgery 2010;148:1170-1176.

12. Wang Y, Lei KR, He YP, Li XL, Ren WW, Zhao CK, et al. Malignancy risk stratification of thyroid nodules: comparisons of four ultrasound Thyroid Imaging Reporting and Data Systems in surgically resected nodules. Sci Rep 2017;7:11560.

13. Titov S, Demenkov PS, Lukyanov SA, Sergiyko SV, Katanyan GA, Veryaskina $Y A$, et al. Preoperative detection of malignancy in fineneedle aspiration cytology (FNAC) smears with indeterminate cytology (Bethesda III, IV) by a combined molecular classifier. J Clin Pathol 2020;73:722-727.

14. Seneldir H, Kir G, Soylemez T, Girgin RB, Ozbay N, Ozen F, et al. Diagnostic accuracy of molecular testing with three molecular markers on thyroid fine-needle aspiration cytology with abnormal category. Diagn Cytopathol 2020;48:507-515.

15. Kumar N, Gupta R, Gupta S. Molecular testing in diagnosis of indeterminate thyroid cytology: trends and drivers. Diagn Cytopathol 2020;48:1144-1151.

16. Goldner WS, Angell TE, McAdoo SL, Babiarz J, Sadow PM, Nabhan $\mathrm{FA}$, et al. Molecular variants and their risks for malignancy in cytologically indeterminate thyroid nodules. Thyroid 2019;29:15941605.

17. Ferrari SM, Fallahi P, Ruffilli I, Elia G, Ragusa F, Paparo SR, et al. Molecular testing in the diagnosis of differentiated thyroid carcinomas. Gland Surg 2018;7(Suppl 1):S19-S29.

18. Eszlinger M, Lau L, Ghaznavi S, Symonds C, Chandarana SP, Khalil M, et al. Molecular profiling of thyroid nodule fine-needle aspiration cytology. Nat Rev Endocrinol 2017;13:415-424.

19. Decaussin-Petrucci M, Descotes F, Depaepe L, Lapras V, Denier ML, Borson-Chazot $F$, et al. Molecular testing of BRAF, RAS and TERT on thyroid FNAs with indeterminate cytology improves diagnostic accuracy. Cytopathology 2017;28:482-487.

20. Nikiforov YE, Baloch ZW. Clinical validation of the ThyroSeq v3 genomic classifier in thyroid nodules with indeterminate FNA cytology. Cancer Cytopathol 2019;127:225-230.

21. Nikiforov YE, Nikiforova MN. Molecular genetics and diagnosis of thyroid cancer. Nat Rev Endocrinol 2011;7:569-580.

22. Giordano TJ, Beaudenon-Huibregtse S, Shinde R, Langfield L, Vinco $M$, Laosinchai-Wolf $W$, et al. Molecular testing for oncogenic gene mutations in thyroid lesions: a case-control validation study in 413 postsurgical specimens. Hum Pathol 2014;45:1339-1347.

23. Rossi ED, Pantanowitz $L$, Faquin WC. The role of molecular testing for the indeterminate thyroid FNA. Genes (Basel) 2019;10:736.

24. Thompson LD. Ninety-four cases of encapsulated follicular variant of papillary thyroid carcinoma: a name change to noninvasive follicular thyroid neoplasm with papillary-like nuclear features would help prevent overtreatment. Mod Pathol 2016;29:698-707.

25. Bychkov A, Jung CK, Liu Z, Kakudo K. Noninvasive follicular thyroid neoplasm with papillary-like nuclear features in Asian practice: perspectives for surgical pathology and cytopathology. Endocr Pathol 2018;29:276-288.

26. Jabar ASS, Koteshwara P, Andrade J. Diagnostic reliability of the Thyroid Imaging Reporting and Data System (TI-RADS) in routine practice. Pol J Radiol 2019;84:e274-e280.

27. Hahn SY, Shin JH, Lim HK, Jung SL, Oh YL, Choi IH, et al. Preoperative differentiation between noninvasive follicular thyroid neoplasm with papillary-like nuclear features (NIFTP) and nonNIFTP. Clin Endocrinol (Oxf) 2017;86:444-450.

28. Liu R, Gao L, Xia Y, Li X, Liao Q, Jiang Y, et al. Three ultrasound phenotypes of non-invasive follicular thyroid neoplasm with papillary-like nuclear features proposed for imaging-pathology analysis: single center experience. Gland Surg 2021;10:307-318.

29. Strickland KC, Eszlinger M, Paschke R, Angell TE, Alexander EK, Marqusee $E$, et al. Molecular testing of nodules with a suspicious or malignant cytologic diagnosis in the setting of non-invasive follicular thyroid neoplasm with papillary-like nuclear features (NIFTP). Endocr Pathol 2018;29:68-74.

30. Rivera M, Ricarte-Filho J, Knauf J, Shaha A, Tuttle M, Fagin JA, et al. Molecular genotyping of papillary thyroid carcinoma follicular variant according to its histological subtypes (encapsulated vs infiltrative) reveals distinct BRAF and RAS mutation patterns. Mod Pathol 2010;23:1191-1200.

31. Xing M. Clinical utility of RAS mutations in thyroid cancer: a blurred picture now emerging clearer. BMC Med 2016;14:12.

32. Consiglio CR, Cotugno N, Sardh F, Pou C, Amodio D, Rodriguez L, et al. The immunology of multisystem inflammatory syndrome in children with COVID-19. Cell 2020;183:968-981.

33. Ihnatsenka B, Boezaart AP. Ultrasound: Basic understanding and learning the language. Int J Shoulder Surg 2010;4:55-62.

34. Gul K, Ersoy R, Dirikoc A, Korukluoglu B, Ersoy PE, Aydin R, et al. Ultrasonographic evaluation of thyroid nodules: comparison of ultrasonographic, cytological, and histopathological findings. Endocrine 2009;36:464-472.

35. Cappelli C, Castellano M, Pirola I, Cumetti D, Agosti B, Gandossi $E$, et al. The predictive value of ultrasound findings in the management of thyroid nodules. QJM 2007;100:29-35.

36. Na DG, Baek JH, Sung JY, Kim JH, Kim JK, Choi YJ, et al. Thyroid Imaging Reporting and Data System risk stratification of thyroid nodules: categorization based on solidity and echogenicity. Thyroid 
2016;26:562-572.

37. Lau RP, Paulsen JD, Brandler TC, Liu CZ, Simsir A, Zhou F. Impact of the reclassification of "noninvasive encapsulated follicular variant of papillary thyroid carcinoma" to "noninvasive follicular thyroid neoplasm with papillary-like nuclear features" on the Bethesda System for Reporting Thyroid Cytopathology: a large academic institution's experience. Am J Clin Pathol 2017;149:50-54. 